\title{
Prevalência de brucelose e tuberculose na região nordeste do estado do Rio Grande do Sul
}

Leonardo Luiz Dametto; Eloise Bertoglio, Sergio Pauls, Miguel Spagnol, Elci Lotar Dickel, Doglas Ernani Vansetto, Daniela dos Santos de Oliveira, Rogério Carvalho Souza, Rafahel Carvalho de Souza

LMS Assessoria Veterinária, Tapejara, RS, Brasil

*Autor correspondente

e-mail: lldametto@yahoo.com.br

\section{Resumo}

Brucelose e tuberculose são doenças infectocontagiosas causadas pelas bactérias Brucella abortus e Mycobacterium bovis, respectivamente, que afetam bovinos e bubalinos. São zoonoses de distribuição universal e por isso infectam o homem através da ingestão de leite cru e seus derivados, consumo de carne contaminada ou também por contato com animais enfermos ou com material de aborto. A brucelose, transmitida entre bovinos por via oral e genital, tem como sintomas o aborto, nascimento prematuro, esterilidade e baixa produção de leite. A tuberculose, disseminada entre bovinos principalmente por via respiratória, caracteriza-se pelo desenvolvimento progressivo de lesões granulomas nodulares, que podem se localizar em qualquer órgão ou tecido. 0 presente trabalho teve por objetivo avaliar a prevalência de brucelose e tuberculose em bovinos de leite na região nordeste do estado do Rio Grande do Sul. Os testes foram realizados por médicos veterinários habilitados pelo Ministério da Agricultura, Pecuária e Abastecimento (MAPA), no período entre junho de 2009 e dezembro de 2016. Foram realizados 9.370 testes para brucelose e 12.686 para tuberculose, em 326 propriedades de 26 municípios. Para a brucelose foi utilizado o teste de triagem do antígeno acidificado tamponado (AAT), que é sensível e de fácil execução. Entretanto, quando a amostra se apresentava positiva ao AAT, ela era encaminhada a um laboratório oficial credenciado para exame confirmatório, o 2-mercaptoetanol. No caso da tuberculose foi utilizado o teste cervical comparativo, que considera como animal positivo aquele que apresentar uma diferença entre delta B menos delta A maior ou igual a 4 milímetros. Todos os testes realizados procederam de acordo com as normas do Programa Nacional de Controle e Erradicação da Brucelose e Tuberculose Animal (PNCEBT).Dos 9.370 animais submetidos ao teste de ATT, somente cinco apresentaram reação positiva após confirmação pelo 2-mercaptoetanol, em quatro propriedades diferentes, ocorrendo, assim, a prevalência de 0,05\% de animais positivos e foco de infecção de 1,22\% das propriedades. Já dos 12.686 animais submetidos ao teste 
para tuberculose, 66 reagiram positivamente em 11 propriedades, apresentando uma prevalência de 0,52\% animais positivos e 3,37\% focos de infecção. Conclui-se que a brucelose e tuberculose embora consideradas doenças seculares, ainda estão presentes nos rebanhos atuais e devem ser encaradas com mais tenacidade pelos órgãos oficiais, produtores rurais e médicos veterinários, pois além de serem um problema para a propriedade rural e para a indústria, são também uma questão de saúde pública. 